\title{
SPECIFICS OF BEHAVIOR AND CALCULATION OF ELASTOMERIC SHOCK ABSORBER UNDER IMPACT LOADING
}

\author{
Svetlana Polukoshko ${ }^{1}$, Andris Martinovs ${ }^{2}$, Vladimirs Gonca ${ }^{3}$ \\ ${ }^{1}$ Ventspils University College, Latvia; ${ }^{2}$ Rezekne Academy of Technologies, Latvia; \\ ${ }^{3}$ Riga Technical University, Latvia \\ pol.svet@inbox.lv, andris.martinovs@rta.lv, vladimirs.gonca@rtu.lv
}

\begin{abstract}
In this paper the important for the design of shock-absorbers case of a perfectly rigid body impact with a viscoelastic incompressible body is considered. Mathematical apparatus for calculating the parameters of impact of a rigid body with a highly- elastic rod is developed, taking into account the peculiarities of the behavior of elastomers under fast loading. An analytical solution was obtained for longitudinal impact on a vertically disposed rod. The solution was fulfilled by means of the Bubnov- Galerkin variational method, reducing the problem to solving of the integro-differential equation for given boundary and initial conditions The solution is received for the exponential relaxation kernel for the Maxwell model of a highly-elastic material, it describes the process of damped longitudinal vibration, taking into account the effect of creep caused by the instantaneous impact loading. Based on the equation of vibratory motion the equations of velocity and acceleration are received, which are used for stress-strain behavior analysis of rubber damper. A numerical example of an axial tensile impact on a viscoelastic shock-absorber in the form of a cylindrical rod is given with the plots of time dependence of displacement, velocity, and acceleration of the impact end of the rod are provided, the possibility of using them for analyzing the shock absorber is demonstrated.
\end{abstract}

Keywords: shock absorber, longitudinal impact, elastomers, rheological model, relaxation kernel.

\section{Introduction}

Impact phenomenon arises when moving solid bodies are colliding with each other or with fixed obstacles. For the modern technology impact processes are of great importance. The time intervals, during which the impact is lasting, are usually very small, and the resulting contact forces are very large. In connection with this anti-shock insulation is one of the main means of improving the reliability of the equipment. For manufacturing of shock absorbers elastomeric materials (natural and synthetic rubber) are widely used because of their specific properties: high elasticity, low volume compressibility, linear relationship between stress and strain up to strain of $15 \div 20 \%$, resistance to environmental factors, good dynamic properties. The high elasticity of rubbers allows them to withstand large elongation without breaking. Elastomeric materials have specific features of mechanical properties: alongside with the instantaneous elastic deformation, these materials exhibit retarding elastic deformation, viscous flow (creep) and relaxation [1-3].

Rubber is a material that has clearly defined relaxation properties, so its mechanical properties strongly depend on the time of application of external loads. If the duration of the force causing a deformation equal to the time of relaxation processes in the rubber, the elastic deformation comes in full force, and this mode of deformation will correspond to well-defined modulus of rubber. When rate of deforming load application increases, the modulus of elasticity will be changing, and its magnitude will be more than elastic modulus for the mode with full implementation of the elastic process. As the duration of impact is small, relaxaion must be taken into account for calculation of the impact parametrs [4].

In order to describe the behaviour of elastomeric material under dynamic loading most authors use the mechanical models of materials, which simplify the relationship between stress and strain in time. It is assumed that this equation is a linear with constant coefficients, and all features of the mechanical behavior may be described by a system combining of two basic types of mechanical elements: elastic and viscous [4-7].

During solving the problems of the impact in vibration isolation equipment, there are two types of deformations distinguished: total deformations of elastic elements and local deformations of colliding masses (inertial elements). If the contact forces between the masses are of interest, local deformation is necessary. To calculate shock isolators, it may be assumed that deformations of the masses themselves do not occur, and the action time of the forces is small in comparison with the oscillation time in the elastic element. 
In the given paper the perfectly rigid body impact with a vertically disposed bar of viscoelastic material is considered. The solution was fulfilled by means of the Bubnov-Galerkin variational method, the problem is reduced to solving the integro-differential equation for given boundary and initial conditions. The solution is obtained for the exponential relaxation kernel for the Maxwell model of a high-elastic material.

The aim of this work is to show the possibility of analytical solving of the impact problem of elastomeric material in nonlinear statement.

\section{Materials and methods}

The simplest model problems are one-dimensional linear problems of the impact loading of viscoelastic rods that allow an analytic solution. More complex problems may be solved by numerical methods, such as finite element and finite difference methods.

For solving the nonstationary dynamic viscoelastic problems, the Laplace and Fourier transform methods are used, but under general models of linear viscoelastic behavior of rubber, the process of inversion of images is associated with considerable mathematical difficulties. Therefore, preference should be given to variational methods based on the application of the principle of the virtual work of Lagrange, the Bubnov-Galerkin method, and others. With this approach, the eigenfunctions of the corresponding elastic problems are used as the coordinate functions [8;9].

Thus, the use of eigenfunctions in the Ritz procedure allows to frame a solution that identically satisfies the coordinate part of the equations of motion and the homogeneous boundary conditions of the problem, and also to seek a solution in the form of eigen mode decomposition in the case of forced motion $[10 ; 11]$.

In Fig. 1 a scheme of impact is given for two cases: tension impact and compression impact of a rigid body of mass $M$. A cylindrical rod of highly-elastomeric material, with the length $h$ and crosssectional area $A$, is located vertically. Displacement along $z$-axis is noted $w$.
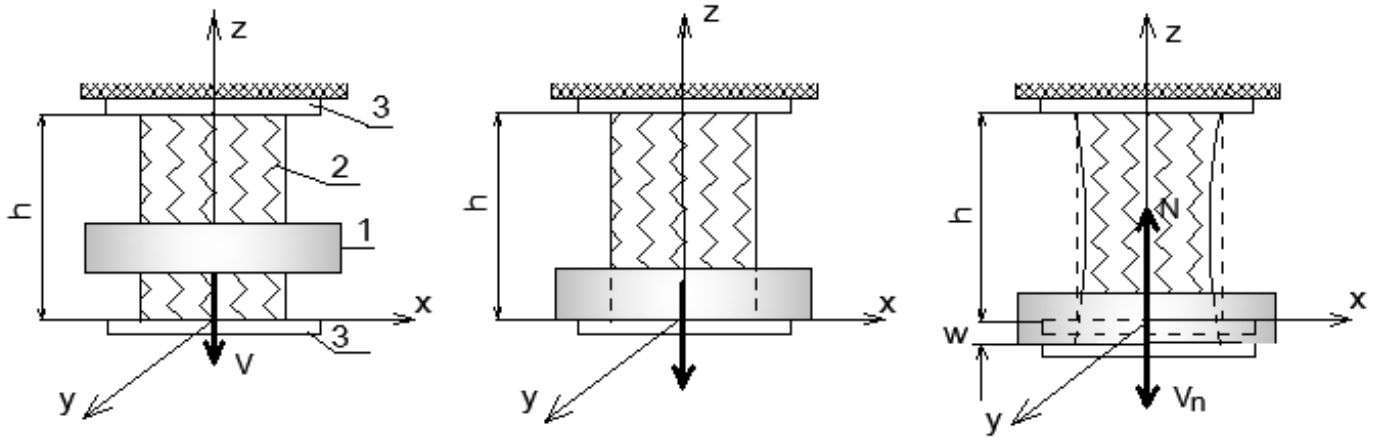

a) tension impact
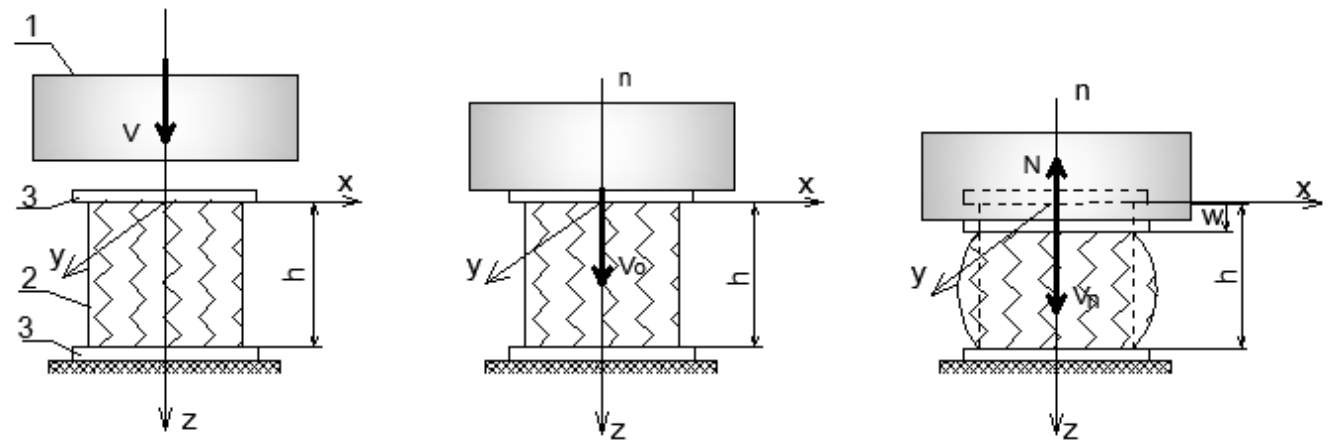

b) compression impact

Fig. 1. Scheme of impact of mass on vertically located rod: 1 - impact body; 2 - cylindrical rod of highly-elastomeric material; 3 - reinforcing plate 
The impact of a rigid body of mass $M$ with a rod of viscoelastic material is described by integrodifferential equation:

$$
E^{*} \frac{\partial^{2} \sigma_{z}}{\partial z^{2}}=\rho \frac{\partial^{2} w}{\partial t^{2}} \text { or } E^{*} \frac{\partial^{2} w_{z}}{\partial z^{2}}=c^{-2} \frac{\partial^{2} w}{\partial t^{2}},
$$

where $\sigma_{z}=E \varepsilon_{z}=E \frac{\partial w}{\partial z},-$ Hooke's law;

$c=\sqrt{E / \rho}$ - phase velocity of longitudinal elastic waves in the rod material;

$E$ - Young's modulus of elasticity;

$E^{*}$ - integrooperator:

$$
E^{*}(\bullet)=(\bullet)-\int_{0}^{t} \Lambda(t-\xi)[\bullet(\xi)] d \xi
$$

For elastomeric materials as the kernel $\Lambda(t)$ in the operator $E^{*}(\bullet)$ is used the exponential kernel

$$
\Lambda(t)=A E^{-\beta t} .
$$

Taking into account (2) the equation (1) may be written as:

$$
\frac{\partial^{2} w}{\partial z^{2}}-\int_{0}^{t} \Lambda(t-\xi) \frac{\partial^{2} w}{\partial z^{2}}(\xi) d \xi=\frac{\rho}{E} \frac{\partial^{2} w}{\partial t^{2}}
$$

with the boundary conditions:

$$
w(z=h)=0, E A\left\{\frac{\partial w}{\partial z}-\int_{0}^{t} \Lambda(t-\xi) \frac{\partial w}{\partial z}(\xi) d \xi\right\}=-M g-m \frac{\partial^{2} w}{\partial t^{2}}, z=0,
$$

where $m=\rho A h-$ mass of rod;

$\rho$ - material density;

and with the initial conditions $(t=0)$ :

$$
w=0, \frac{\partial w}{\partial t}=0 \text { if } 0<z \leq h, \frac{\partial w}{\partial t}=v_{0} \text { if } z=0 .
$$

The solution of the nonstationary problem (4) - (6) is sought in the form:

$$
w=\sum_{n=1}^{\infty} f_{n}(t) \sin \left(\gamma_{n}(h-z)\right),
$$

where $\sin \left(\gamma_{n}(h-z)\right)$ - eigenfunctions of the problem of the rod vibration with load at the end;

$\gamma_{n}$ - eigenvalues as roots of the transcendental equation;

$$
h \gamma_{n} \operatorname{tg}\left(h \gamma_{n} h\right)-\frac{m}{M}=0 .
$$

Using the Bubnov - Galerkin method, the solution of equation (1), taking into account (7), is reduced to inhomogeneous integro-differential equations for the definition of functions $f_{n}(t)$ :

$$
\begin{aligned}
& \frac{d^{2} f_{n}(t)}{d t^{2}}+a_{n}^{2}\left[f_{n}(t)-\int_{0}^{t} \Lambda(t-\xi) f_{n}(\xi) d \xi\right]=\vartheta_{n} H(t), \\
& \alpha_{n}^{2}=\gamma_{n}^{2} c^{2}=\gamma_{n}^{2} \frac{E}{\rho}, \vartheta_{n}=\frac{2 g \cos \left(\gamma_{n} h\right)}{\gamma_{n} h+\sin \left(\gamma_{n} h\right) \cos \left(\gamma_{n} h\right)}
\end{aligned}
$$

In equation (9) $H(t)$ is the Heaviside function. 
Taking into account (6), the initial conditions for equation (9) are written as:

$$
f_{n}(0)=0, \frac{d f_{n}(0)}{d t}=\frac{2 v_{0} \cos \left(\gamma_{n} h\right)}{\gamma_{n} h+\sin \left(\gamma_{n} h\right) \cos \left(\gamma_{n} h\right)}=v_{0} \frac{\vartheta_{n}}{g} .
$$

Highly elastic properties of elastomers for many problems are satisfactorily described using the exponential kernel $\Lambda(t)=A e^{-\beta t}$. For obtaining of the exact solution of (9), the exponential kernel with $A=\beta$ is used, which corresponds to the Maxwell model.

The exact solution of equation (9) in written in the form:

$$
f_{n}(t)=\psi_{n}(t) \frac{d f_{n}(0)}{d t}+\frac{d \psi_{n}(t)}{\partial t} f_{n}(0)+\int_{0}^{t} \psi_{n}(t-\xi) \vartheta_{n} H(\xi) d \xi,
$$

where the function $\psi_{n}(t)$ is a solution of the homogeneous equation (9). This solution has the form:

$$
\psi_{n}(t)=C_{1 n}+e^{-\frac{\beta}{2} t}\left[C_{2 n} \cos \left(\omega_{n} t\right)+C_{3 n} \sin \left(\omega_{n} t\right)\right],
$$

under the initial conditions

$$
\psi_{n}(t=0)=0, \frac{d \psi_{n}(t=0)}{d t}=1, \frac{d^{2} \psi_{n}(t=0)}{d t^{2}}=0 .
$$

The constants $C_{1 n}, C_{2 n}, C_{3 n}$, taking into account (13) are written:

$$
C_{1 n}=\frac{\beta_{n}}{\alpha_{n}{ }^{2}}, C_{2 n}=-C_{1 n}, C_{3 n}=\frac{2 \alpha_{n}{ }^{2}-\beta_{n}{ }^{2}}{2 \alpha_{n}{ }^{2} \omega_{n}} \text {, where } \omega_{n}{ }^{2}=\alpha_{n}{ }^{2}-\frac{\beta_{n}}{4} \text {. }
$$

From the equations $(11)-(14)$ the desired solution for the function $f_{n}(t)$ has the form

$$
\begin{aligned}
& f_{n}(t)=\frac{d f_{n}(0)}{d t} \frac{\beta}{a_{n}^{2}}+\frac{d f_{n}(0)}{d t} e^{\frac{-\beta}{2} t}\left[\frac{2 a_{n}^{2}-\beta^{2}}{2 a_{n}^{2} \omega_{n}} \sin \left(\omega_{n} t\right)-\frac{\beta}{a_{n}^{2}} \cos \left(\omega_{n} t\right)\right]+ \\
& +\frac{\beta \vartheta_{n}}{2 a_{n}^{2} \omega_{n}}\left(\frac{\beta^{2}}{a_{n}^{2}}-\frac{3}{2}\right) e^{\frac{-\beta}{2} t} \sin \left(\omega_{n} t\right)+\frac{\vartheta_{n}}{a_{n}^{2}}\left(\frac{\beta^{2}}{a_{n}^{2}}-1\right) e^{\frac{-\beta}{2} t} \cos \left(\omega_{n} t\right)+\frac{\beta \vartheta_{n}}{a_{n}{ }^{2}} t+\frac{\vartheta_{n}}{a_{n}{ }^{2}}\left(1-\frac{\beta^{2}}{a_{n}^{2}}\right)
\end{aligned}
$$

The solutions (7) and (15) describe the process of damped oscillations, taking into account the effect of creep caused by the instantaneous application of the load.

The algorithm of the problem solution is as follows:

1) to find $h \gamma_{n}$ from equation (8);

2) to find $\gamma_{n}, a_{n}^{2}, \vartheta_{n}, f_{n}(0), d f_{n}(0) / d t, \omega_{n}$;

3 ) in accordance with equations (15) find $f_{1}(t), f_{2 n}(t), \ldots f_{n}(t)$ and according to (7) find $w$ for any section of the rubber rod. If we know the motion in $\mathrm{z}$ - direction as the function of time $w(t)$, we can define the velocity and acceleration of sections, and consequently, the acting impulsive force.

\section{Results and discussion}

The example of numerical solution of this problem for the cylindrical rubber rod with the height $h=0.20 \mathrm{~m}$, radius $r=0.06 \mathrm{~m}$, sectional area $S=0.0113 \mathrm{~m}^{2}$, Young's modulus $E=2.4 \mathrm{MPa}$, specific weight $\rho=1200 \mathrm{~kg} \cdot \mathrm{m}^{-3}$, mass $m=2.714 \mathrm{~kg}$, Maxwell kernel parameters $A=\beta=6$. Rubber rod mass and impact body mass ratio is $m / M=0.5$, velocity at the beginning of the tension impact is $v_{0}=-$ $1.5 \mathrm{~m} \cdot \mathrm{s}^{-1}$.

The problem is solved with help of Mathcad -15 program, the results are given below. Displacement, velocity, acceleration and force are calculated for the section with the coordinate $z=0$, i.e. the rod impact end. Number of the members of equation (7) $n$ is assumed 20, further increasing 
does not influence the results, it is usually enough to have six or seven roots for velocity and displacement calculation.

In Fig. 2 the method of solution of transcendental equation (8) is presented for the ratio $m / M=0.5$ : here we can see the first twenty roots, the difference between the numerical values is approaching $\pi$.

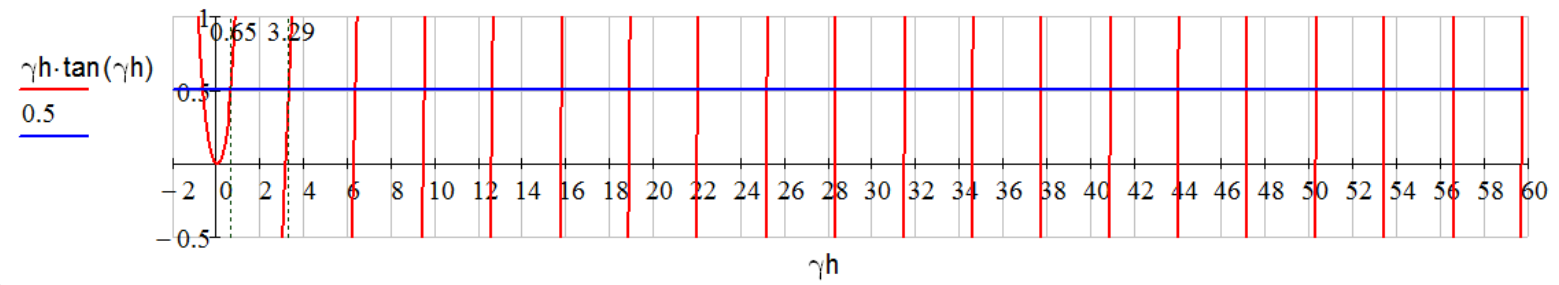

Fig. 2. Definition of roots of transcendental equation

In Fig. 3 the plot of dependence of the displacement on time for the first 0.2 seconds is presented, it is shown that the maximum displacement is $5.8 \mathrm{~mm}$.

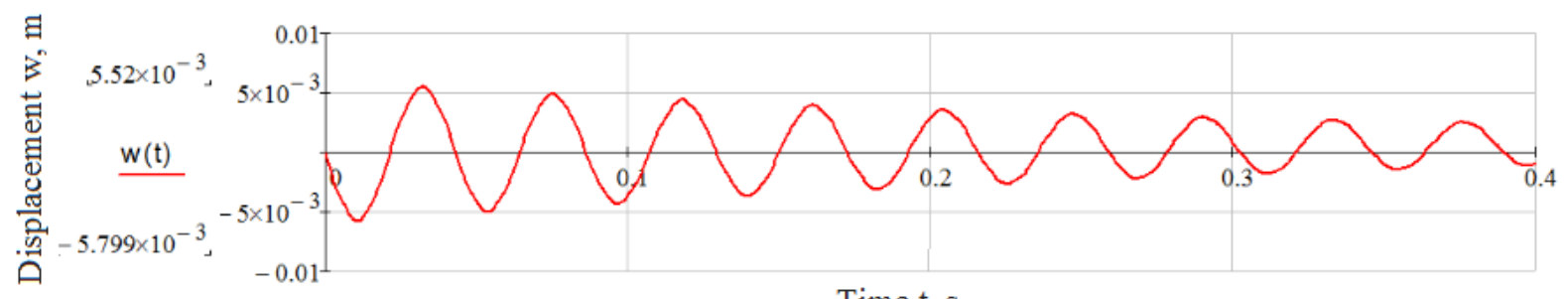

Time $t, s$

Fig. 3. Plot of displacement of impact end of rod dependence on time

In Fig. 4 plots of the dependence of the velocity of the rod impact end on time are shown. At the end of the impact the velocity is equal to zero, in our case this time is 1.6 seconds, if we ignore the velocity of fraction of millimetres per second, which can last a long time.

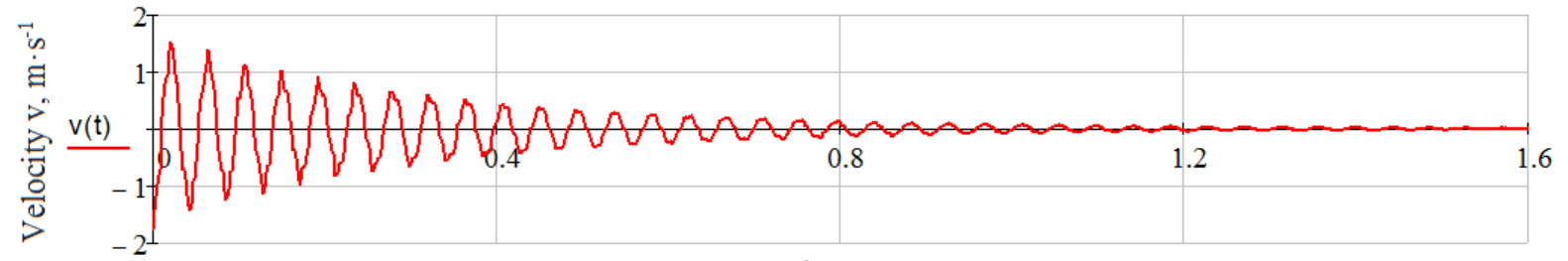

Time $\mathrm{t}, \mathrm{s}$

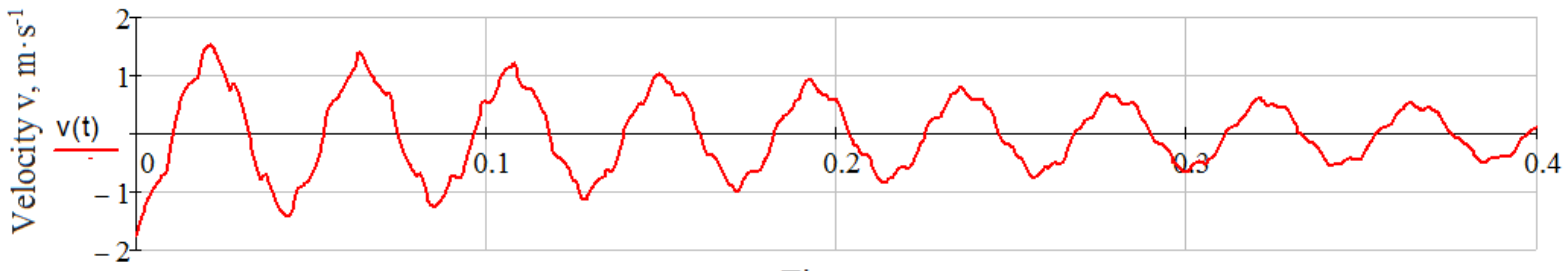

Time $t, s$

Fig. 4. Plots of velocity of impact end of rod depending on time

Fig. 5 shows the acceleration - time dependence in the first 0.2 seconds.

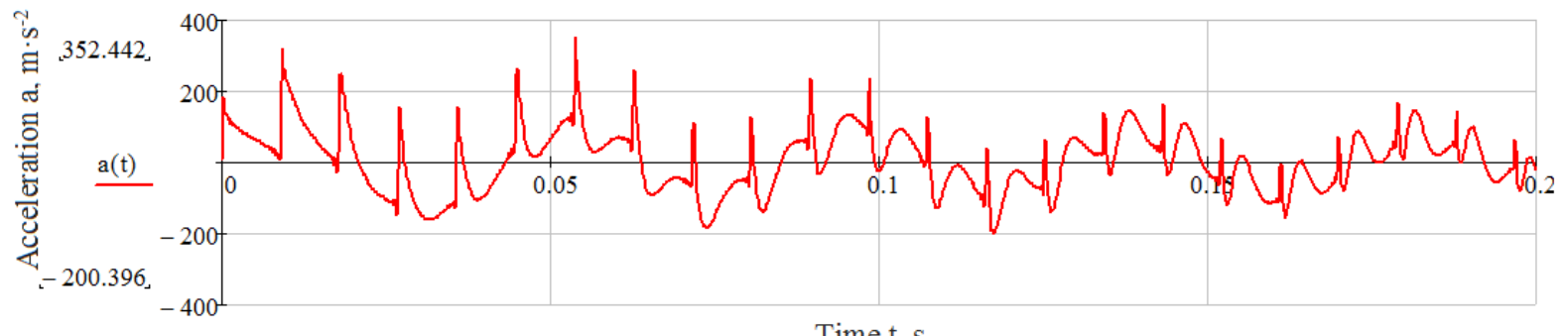

Time t, s

Fig. 5. Plot of acceleration of impact end of rod depending on time 
Maximal acceleration is equal to $352 \mathrm{~m} \cdot \mathrm{s}^{-2}$, accordingly, the maximal force is $1908 \mathrm{~N}$ and the maximal stress obtained equals to $\sigma=169 \mathrm{kPa}$.

Maximal tensile displacement is equal to $5.8 \mathrm{~mm}$, so the relative deformation is small enough $2.9 \%$. Using the formula for static displacement according to the Hooke's law the required force may be calculated, it is obtained equal to $786 \mathrm{~N}$ :

$$
N_{s t}=\frac{w E A}{h}=\frac{5.8 \cdot 10^{-3} \cdot 2.4 \cdot 10^{6} \cdot 0.0113}{0.2}=786 \mathrm{~N} .
$$

With the form factor for a cylindrical cross section $k_{f}=1.25$ it is equal to $983 \mathrm{~N}$. This results in the static force twice less than the dynamic force at the end of the rod.

The solution in accordance with equations (15), (7) has physical clearness: it describes the process of damping of vibration caused by the instantaneous application of the load.

The results may be used for designing of new shock-absorbers or for checking the operating capability of the existing one: to define their stress and strain characteristics. If we know the maximal acceleration, we can define the maximal impact force and compressive or tensile stress in the damper cros-sections; duration of impact is defined upon completion the wave process in the rod.

There are no published results of analytical solutions of the visco-elastic problem, but the results of numerical solutions of analogical problems, received by finite elements methods, are very similar to the foregoing [9].

\section{Conclusions}

In the given paper an analytical method for solving the longitudinal impact problem for a body with viscoelastic properties is presented. The relaxation kernel of the elastomeric material is assumed to be exponential in accordance with the Maxwell model. Thus, the problem of longitudinal impact on the rubber shock absorber may be quickly solved, if the properties of the elastomeric material are known. In this work the tensile impact of a rigid body with a rubber rod is discussed, calculation of the compression impact is analogical.

The displacement, velocity, acceleration and the impact forces in any cross section of the shock absorber may be determined, as well as duration of the impact.

The problem for highly elastic bodies with more complex kernel may be solved numerically by means of the finite difference procedure or the finite elements method.

The next stage of this work is an experimental study of such impact and comparison of the experimental and theoretical results.

\section{References}

[1] Gent A.N. Engineering with Rubber: How to Design Rubber Components. Munich: Carl Hanser Verlag, 2011. $428 \mathrm{p}$.

[2] Kelly, J.M. and Konstantinidas, D.A. Mechanics of Rubber Bearings for Seismic and Vibration Isolation. UK: John Wiley \& Sons, 2011. 240 p.

[3] Потураев В.Н., Дырда В.И. Резиновые детали машин (Rubber Machine Elements). Moscow: Mashinostrojenie, 1977. 217 p. (In Russian).

[4] Илюшин А.А., Победря В.Е. Основы математической теории термовязко-упругости (Fundamentals of mathematical theory thermo-viscoelasticity), Moscow: Nauka, 1970. 281 p.

[5] Assie A.E., Eltaher M.A., Mahmoud F.F. Modeling of viscoelastic contact-impact problems. Applied Mathematical Modelling, 34, 2010. pp. 2336-2352.

[6] Li K., Darby A. Modelling a buffered impact damper system using a spring-damper model of impact. Structural Control and Health Monitoring, 16 (3), 2009. pp. 287-302.

[7] Bhuiyan A. R., Amin A. F. M. S, Hossain T. and Okui Y. Nonlinear viscosity law for ratedependent response of high damping rubber: FE implementation and verification, Constitutive Models for Rubber, V - Boukamel, Laiarinandrasana, Meo \& Verron (eds), Taylor \& Francis Group, London, 2008, pp. 279 - 284. 
[8] Лепетов В.А. Резиновые технические изделия (Rubber technical products). Moscow: Chemistry, 1972. 328 p. (In Russian).

[9] Ляпунов В.Т., Лавендел Э.Э., Шляпочников С.А. Резиновые виброизоляторы (Rubber vibration isolators). Leningrad: Sudostrojenie, 1988. 216 p. (In Russian).

[10] Лавендел, Э.Э. Расчет резинотехнических изделий (Design of Fabricated Rubber Products). Moscow: Mashinostroenie, 1976. 182 p. (In Russian).

[11]Лавендел Э.Э., Дымников С.И., Павловский А.А., Сниегс М.И. Прикладные методы расчёта изделий из высокоэластичных материалов (Applied methods of calculating the product of highly elastic materials). Riga: Zinatne, 1980. 238 p. (In Russian). 